\title{
A Study on Pharmacological Agents Used among Patients with Osteoporosis
}

\author{
Muhammed Fazil OP' ${ }^{1}$, Ashwin Shetty ${ }^{2}$, Sharad Chand ${ }^{1}$, Nandakumar UP', Juno J Joel ${ }^{1, *}$ \\ 'Department of Pharmacy Practice, NITTE Gulabi Shetty Memorial Institute of Pharmaceutical Sciences (NGSMIPS), NITTE (Deemed to be University), Deralakatte, \\ Mangaluru, Karnataka, INDIA. \\ 2Department of Orthopedics, Justice KS Hegde Charitable Hospital, NITTE (Deemed to be University), Deralakatte, Mangaluru, Karnataka, INDIA.
}

\begin{abstract}
Objectives: The study was conducted to analyse the prescription pattern of the drugs used to treat osteoporosis among patients in the orthopaedics department of a tertiary care hospital. Methods: This was a retrospective observational study conducted at the department of orthopaedics in a tertiary care teaching hospital for a period of eight months. A total of 180 patients were enrolled after obtaining the ethical committee approval. The details on the age, gender, symptoms of the disease, and prescribed drugs were collected and analysed using descriptive statistics. Results: Out of 180 enrolled patients, females $(96.7 \%)$ outnumbered the males $(3.3 \%)$. The majority of patients $(53.8 \%)$ were found between $56-75$ years of age. Most common clinical symptom was back pain $(71.67 \%)$, followed by pain in hip joints (11.67\%). Non-steroidal anti-inflammatory drugs $(26.67 \%)$ were widely prescribed, followed by calcium and Vitamin combination (23.93\%), and antacids (20.27\%). Conclusion: Non-steroidal anti-inflammatory
\end{abstract}

drugs, calcium and Vitamin preparations and antacids were the commonly prescribed drugs among the study population. Studies conducted on prescription patterns assist an evaluation of drug utilization and facilitates an understanding of the on-going trends in prescribing practice. Key words: Osteoporosis, Calcium, Vitamins, Back pain, NSAIDs.

Correspondence

Dr. Juno J. Joel,

Assistant Professor, Department of Pharmacy Practice, NITTE Gulabi Shetty Memorial Institute of Pharmaceutical Sciences (NGSMIPS), NITTE (Deemed to be University), Deralakatte, Mangaluru, Karnataka, INDIA.

Email: junojoel@nitte.edu.in

DOI: 10.5530/jyp.2021.13.37

\section{INTRODUCTION}

Osteoporosis is a disease mainly affecting the females and elderly population, and is characterized by low bone mass and disruption of bone microarchitecture. ${ }^{1}$ It is a bone metabolic disorder in which there is reduced bone mineral density, leading to increased skeletal fragility and fracture risk. ${ }^{2}$ Osteoporosis is sometimes called a silent disease because bone loss occurs without any symptoms for an extended period. Since osteoporotic fractures occur in those situations where healthy people would not usually break a bone, it is also known as fragility fractures. It occurs due to an imbalance between demineralization and remineralization of the bone. ${ }^{1}$ However, the female gender is still the major risk factor for osteoporosis. During the reproductive age, bone mass density is well maintained through the bone formation by osteoblasts and bone resorption by osteoclasts. In premature menopause or during the post-menopause stage, the osteoclast activity increases by many folds compared to osteoblast, leading to osteoporosis. Worldwide, 1 out of 3 women is above 50 years of age. In India, osteoporosis among women aged above 50 years is around $20 \%$, accounting for almost 46 million cases. ${ }^{3}$ Although India abounds in sunlight, the prevalence of Vitamin D deficiency, the occurrence of early menopause and the regular consumption of an imbalanced diet are some of the risk factors for osteoporosis. Although there are several diagnostic procedures to detect osteoporosis still the patients are not diagnosed adequately due to lack of symptoms. In addition, the gold standard diagnostic tests like dualenergy X-ray absorptiometry are either very expensive or inaccessible to the general population resulting in the poor diagnosis of the disease. Due to these reasons, research on osteoporosis is still in its infancy. ${ }^{4,5}$
The clinical profiling and prescription pattern studies helps to identify the drug utilization pattern and to study the on-going trends in the therapy. 6,7 The findings of such prescription pattern studies can be used to compare the survey results with the guidelines. At times, these findings also help in rationalizing the drug therapy, ensuring the therapy's safety and efficacy. ${ }^{8,9}$ Therefore, we aimed to study the prescribing pattern of the drugs used to treat osteoporosis in a tertiary care teaching hospital.

\section{MATERIALS AND METHODS}

A retrospective study of eight months duration from August 2019-April 2020 was conducted in the orthopaedics department of Justice K.S. Hedge Charitable Hospital, situated in the coastal district Dakshina Kannada of South India. The institutional ethics committee of NGSM Institute of Pharmaceutical Sciences has approved the study prior to the data collection (reference number NGSMIPS/IEC/06/2019-20). The minimum required sample size for the study was 180 patients. The required sample size was calculated based on the total hospital admissions and the pilot study conducted before the main study. ${ }^{10,11}$ Patients of either gender, aged above 18 years, diagnosed with osteoporosis were enrolled in the study. The patient with incomplete medical records and life-threatening comorbidities were excluded from the study. The study also excluded pregnant women and lactating mothers. A suitable patient data collection form was designed as per the need of study. The data collection form had three different sections: a) patient demographic details, b) signs and symptoms, laboratory data, and diagnosis of disease, and c) the details on the treatment given and concomitant drugs used to treat the comorbidities. All the relevant information was collected 
from the patient treatment charts obtained from the hospital's medical records department. The data was collected on a daily basis; and was cross-checked to minimize the possible errors. Details on the clinical presentation of the patients, laboratory findings, and drug therapy such as drugs, dosage form, frequency, route of administration, duration of treatment, and the number of drugs per prescription were recorded. The collected data was summarized by using descriptive statistics. The quantitative data including age and gender was calculated using mean and standard deviation.

\section{RESULTS}

\section{Distribution of Patients Based on their Demographic Details}

The study included a total of 180 patients diagnosed with osteoporosis over the last three years. A detailed evaluation of the data collected revealed that $174(96.7 \%)$ were females and only $6(3.3 \%)$ were males, suggesting higher prevalence of osteoporosis among female patients. All patients were classified into three groups based on their age in years. Out of which, osteoporosis was found more prevalent among patients in the age category of 56-75 years, accounting for $n=97(53.8 \%)$ cases. The second most prevalent age group was $35-55$ years, $n=62(34.44 \%)$, and the least number of cases were diagnosed in the age group of 76-95 years, $n=21(11.67 \%)$.

\section{Distribution of Patients based on their Chief Complaints During the Hospital Admission}

The findings of our reveal that, out of the total patients enrolled, $n=129$ (71.67\%) had complaints of back pain followed by hip pain, $n=21$ (11.67\%) and knee pain, $n=18(10.0 \%)$. The patients complaining of wrist pain were the least in the study, $n=2(1.1 \%)$. Table 1 elaborately discusses the complaints of the patients on admission.

\section{Distribution of Patients based on the Details of Drugs Prescribed to Treat Osteoporosis}

The study results showed that the total number of drugs prescribed to treat osteoporosis were $n=656$ among 180 patients, with an average of 3.64 drugs per prescription. It was observed that non-steroidal antiinflammatory drugs (NSAIDs) were prescribed among the majority, $n=175$ (26\%), followed by calcium and Vitamin combinations, $n=157$ (23.93\%) and antacids among $n=133(20.27 \%)$ patients. Muscle relaxants were the least prescribed, $n=33(5.03 \%)$. The details of classes of medications prescribed in the study are depicted in Table 2.

Table 1: Distribution of patients based on their complaints during the hospital admission.

\begin{tabular}{ccc}
\hline Complaints on admission & Frequency $(\mathbf{n})$ & Percentage (\%) \\
\hline Back pain & 129 & 71.67 \\
Hip pain & 21 & 11.67 \\
Knee pain & 18 & 10.00 \\
Multiple joint pain & 15 & 8.33 \\
Lower limb pain & 7 & 3.88 \\
Neck pain & 5 & 2.77 \\
Shoulder pain & 3 & 1.66 \\
Wrist pain & 2 & 1.11 \\
\hline
\end{tabular}

Table 2: Distribution of patients based on the details of drugs prescribed to treat osteoporosis.

\begin{tabular}{|ccc|}
\hline Drugs & Frequency $(\mathbf{n})$ & Percentage (\%) \\
\hline NSAIDs & 175 & 26.67 \\
$\begin{array}{c}\text { Calcium and Vitamin } \\
\text { combination }\end{array}$ & 157 & 23.93 \\
Antacids & 133 & 20.27 \\
Vitamin & 109 & 16.61 \\
Miscellaneous drugs & 49 & 7.46 \\
Muscle relaxant & 33 & 5.03 \\
Total & 656 & 100
\end{tabular}

\section{Distribution of Patients based on the Details of Drugs Prescribed to Treat their Co-Morbidities}

A total of 39 drugs were prescribed to treat the co-morbidities associated with osteoporosis. Among these drugs, antibiotics were prescribed in $n=15(38.46 \%)$ cases, followed by laxatives, $n=10(25.64 \%)$ and antioxidant, $n=9$ (23.07\%). The least prescribed drug belonged to the category of anticonvulsants, $n=5$ (12.82\%).

In addition to the various pharmacological agents prescribed, majority of the patients were advised on non-pharmacological measures and physical therapy interventions during their hospital stay.

\section{DISCUSSION}

In this study, the occurrence of osteoporosis was found to be higher among females (96.7\%), outweighing the males (3.3\%). A study conducted by Tripathy A et al. and Van der Velde RY et al. also showed similar results, where the prevalence was of around 90\% among the females and $10 \%$ among the males. ${ }^{12,13}$ Our study results revealed that a maximum number of patients belonged to the age category of 56-75 years, which had similarity with the study results of Augustine AM et al. where the mean age of the patient was 50-60 years. Another study carried out by Tripathy A et al. also reported that the cases found above the age of 50 years topped the list. ${ }^{12,14}$ In our study, the most common symptom and the reason for hospital admission was back pain, difficulty in walking, difficulty in lifting an object, and hip pain. This can be attributed to the negative calcium balance and weakness of vertebra and other large bones. A study by Tripathy et al. and Ryan P.J et al. showed similar results by reporting $89 \%$ incidence of back pain among their study population. ${ }^{12,15}$

In our study, the most commonly prescribed drugs were NSAIDS, calcium and Vitamins combination and antacids. These results are in accordance with a study conducted by Tang BM et al. which showed that calcium or calcium combined with Vitamin D were used for the therapy of osteoporosis with combinations of NSAIDs. ${ }^{16}$ Research conducted by Augustine AM et al. ${ }^{14}$ also had similar results, where frequently prescribed drugs were NSAIDs, Antiulcer agents, calcium supplements and multi Vitamins. But, contradictory results were reported in a study conducted by Hajcsar EE et al. ${ }^{17}$ Where bisphosphonates were the commonly used drug. The pain presented by the patients during their hospital admission can justify the use of NSAIDs in the current study. A study conducted by Murray $\mathrm{W}$ et al. ${ }^{18}$ showed that continuous treatment with Vitamin $\mathrm{D}$ in postmenopausal osteoporotic women for three years decreased the incidence of vertebral fractures. Another similar study focused on rationalizing the use of Vitamin D and calcium to reduce the symptoms. ${ }^{12}$ Paracetamol, tramadol, aceclofenac were the most commonly prescribed analgesic drugs in research conducted by Vestergaard $\mathrm{P}$ et al. ${ }^{19}$ Even 
though NSAIDs have no role to play with respect to the bone mineral density, they were used in the study for obtaining a better control over the prevailing symptoms.

Some medications used in the treatment of osteoporosis can cause gastric problems including gastric irritation, bloating, oesophageal ulcer and gastric ulcer. This might be the reason for the excess use of antacid in the treatment of osteoporosis. The excessive use of antacid and proton pump inhibitors was noted in a study conducted by Targownik LE et $a l .^{20}$ The same study reported that the risk of osteoporosis increases with excessive and long-term use of proton pump inhibitors. Their results also revealed that the patients who were not on proton pump inhibitors had increased bone mineral density than patients on therapy with proton pump inhibitors.

\section{CONCLUSION}

The present study showed that females were most commonly diagnosed with osteoporosis. The most frequently reported clinical symptoms were back, hip and knee pain. The complaints were treated with NSAIDs and calcium and Vitamin supplements. These drugs were co-prescribed with gastro-protective agents. Several non-pharmacological therapies such as strict exercise were advised to these patients. The cumulative impact of these therapies is expected to significantly improve the patient's quality of life, shorten the frequency of hospital visits and the incidence of long term complications.

\section{ACKNOWLEDGEMENT}

We authors would like to thank NGSM Institute of Pharmaceutical Sciences and Justice K.S. Hegde Charitable Hospital for their support during the research work.

\section{CONFLICT OF INTEREST}

The authors declare no conflict of interest.

\section{ABBREVIATIONS}

NSAIDs: Non-steroidal anti-inflammatory drugs.

\section{REFERENCES}

1. Hernlund E, Svebbom A, Ivergard M, Compston J, Cooper C, Stenmark J, et al. Osteoporosis in the European Union: Medical management, epidemiology and economic burden. A report prepared in collaboration with the international osteoporosis foundation and the European federation of pharmaceutical industry association. Arch Osteoporosis. 2013;8(1):1-15.

2. Mazocco L, Chagas P. Association between body mass index and osteoporosis in women from northwestern Rio Grande do Sul. Revista Brasileira de Reumatologia (English Edition). 2017;57(4):299-305.
3. Khadilkar AV, Mandlik RM. Epidemiology and treatment of osteoporosis in women: An Indian perspective. Int J Womens Health. 2015;7:841-50.

4. Kadam NS, Chiplonkar SA, Khadilkar AV, Khadilkar W. Prevalence of Osteoporosis in Apparently Healthy Adults above 40 Years of Age in Pune City, India. Indian J Endocrinol Metab. 2018;22(1):67-73.

5. MithalA, BansalB, Kyer CS, Ebeling P.TheAsia-pacific regional audit-epidemiology, costs, and burden of osteoporosis in India 2013: A report of international osteoporosis foundation. Indian J Endocrinol Metab. 2014;18(4):449-54.

6. Gouda V, Shastry CS, Mateti UV, Subrahmanya C, Chand S. Study on steroid utilization patterns in general medicine department. Research $\mathrm{J}$ Pharm and Tech. 2019;12(10):4771-6.

7. Al-Jabri MM, Shastry CS, Chand S. Assessment of drug utilization pattern in chronic kidney disease patients in a tertiary care hospital based on who core drug use indicators. JGPT. 2019;11(9):1-9.

8. Chandran BK, Vaddakan K, Altaf M, Shetty V, Chand S, Vijayan A, et al. A retrospective study on prospective usage pattern of analgesics in orthopaedics department of a tertiary care hospital. IJSTR. 2020;9(03):1207-11.

9. Chacko CS, Nandakumar UP, Chand S, et al. Prescribing pattern among out patients of department of obstetrics and gynaecology in a tertiary care hospital. Plant Archives. 2020;20(Spl 02):2249-51.

10. Mohammed HAR, Babu N, Chand S, Nandakur UP, Bharathraj KC. Study on prescription pattern for osteoarthritis in a tertiary care teaching hospital: A retrospective study. Biomedicine. 2020;40(03):353-6.

11. Mehaneesha K, Rishab P, Seetharam SS, Mathias L, Chand S, Nandakumar UP, et al. A retrospective study on drug utilization pattern in management of rheumatoid arthritis. Research J Pharm and Tech. 2020;13(11):5263-6.

12. Tripathy A, Adiga S, Shah HH, Shanbhag TV, Kumar DM. A retrospective study of clinical profile and drug prescribing pattern in osteoporosis in a tertiary care hospital. Int J Pharm Pharm Sci. 2015;7(10):390-3.

13. Velde RYVD, Wyers C, Teesselink E, Geusens PP, Bergh JPVD, Vries FD, et al. Trends in oral anti-osteoporosis drug prescription in the United Kingdom between 1990 and 2012: Variation by age, sex, geographic location and ethnicity. Bone. 2017;94:50-5

14. Augustine AM, Shamrao D, Basnet S, Bhoja AN, Shareef J. Study of drug utilization pattern of calcium, Vitamin D supplements, and anti-osteoporosis drugs in patients with osteoporotic fracture: A prospective cross-sectional study. Asian J Pharm Clin Res. 2018;11(12):370-3.

15. Ryan PJ, Blake G, Herd R, Fogelman I. A clinical profile of back pain and disability in patients with spinal osteoporosis. Bone. 1994;15(1):27-30.

16. Tang BM, Esclik GD, Nowson C, Benoussan A. Use of calcium or calcium in combination with Vitamin D supplementation to prevent fracture and bone loss in people aged 50 years and older: A meta-analysis. Lancet. 2007;370(9588):65766.

17. Hajcsar EE, Hawker G, Bogoch ER. Investigation and treatment of osteoporosis in patients with fragility fractures. CMAJ. 2000;163(7):819-22.

18. Tilyard MW, Spears GF, Thomson J, Dovey S. Treatment of postmenopausal osteoporosis with calcitriol or calcium. N Engl J Med. 1992;326(6):358-62.

19. Vestergaard P, Hermann P, Jensen JE, Eiken P, Mosekilde L. Effects of paracetamol, non-steroidal anti-inflammatory drugs, acetylsalicylic acid and opioids on bone mineral density and risk of fracture: results of the Danish Osteoporosis Prevention Study (DOPS). Osteoporosis International. 2012;23(4):1255-65

20. Targownik LE, Lix LM, Metge CJ, Prior HJ, Leung S, Leslie WD. Use of proton pump inhibitors and risk of osteoporosis-related fractures. CMAJ. 2008;179(4):319-26.

Article History: Submission Date : 16-03-2021; Revised Date : 20-04-2021; Acceptance Date : 04-05-2021.

Cite this article: Fazil MOP, Shetty A, Chand S, Nandakumar UP, Joel JJ. A Study on Pharmacological Agents used among Patients with Osteoporosis. J Young Pharm. 2021;13(2):183-5. 